\title{
Attitudes of university students from Mérida (Spain) to the challenge of climate change
}

\author{
J.M. Vaquero, V.M.S. Carrasco, J. Vaquero-Martínez, M.C. Gallego \\ University of Extremadura
}

Climate change is one of the greatest challenges for our society to face. To assess the state of Science on climate change, the United Nations Environment Program and the World Meteorological Organization created the Intergovernmental Panel on Climate Change (IPCC) in 1988. With 195 member countries, it is also responsible for providing regular scientific reports, future risk estimations, and mitigation options on climate change. Their fifth and last report was published in 2014 (IPCC, 2014) and the IPCC Sixth Assessment Report is expected for 2022. This report shows a wide consensus that the observed increase in global temperature is produced by anthropogenic causes. Because of this fact, very recent social movements, such as the modern "Fridays for Future", have emerged in order to raise awareness and to provide a response to climate change.

Several studies have been published relating climate change and society (Yu et al., 2013; Bray and von Storch, 2016). Some of these studies are based on the idea of climatology as a post-normal science (Bray and Storch, 1999). For example, Ratter et al. (2012) concluded that there was a decline in attention of the western society on climate change in that time. They indicated that such decline could be a manifestation of attention cycles and it may reverse in the future. Recently, von Storch et al. (2019) carried out a survey to learn about the opinions of students about climate change, namely, at the Ocean University of China in Qingdao in 2015-2016, and at the Cluster of Excellence Integrated Climate System Analysis and Prediction of the University of Hamburg in 2017. The responses collected from 87 (Qingdao) and 72 (Hamburg) undergraduates and post-graduates allowed von Stroch et al. (2019) to conclude that the differences in the attitudes between both groups about the roles of science, of the state and of the civil society in facing climate change can be explained by cultural differences. Moreover, although in both surveys most of the respondents attributed climate change to anthropogenic effects, the percentage in the case of Hamburg survey (93\%) was greater than in Qingdao survey (70\%). 


\section{A new study carried out at Mérida (Spain)}

We conducted a new study at the Mérida University Center (CUMe), belonging to the University of Extremadura. This center is located in the city of Mérida $\left(38^{\circ} 54^{\prime} \mathrm{N} 6^{\circ} 20^{\prime} \mathrm{W}\right)$, which is within the region of Extremadura, at the southwest of Spain. In Spain, the state is in charge of the main solutions in environmental problems. Nevertheless, several organizations of the Spanish civil society are carrying out actions against climate change (Llorente et al., 2020). For example, 24 social and environmental Spanish associations joined to create the citizen platform "Coalición Clima" (Climate Coalition). Thus, the Spanish context can be considered typical within the European Union.

Our study was carried out in 5-16 November 2020 during the first semester of the academic year 2020/2021. The number of participants was 100, slightly greater than that in the Hamburg and Qingdao surveys (von Storch et al., 2019). We highlight that around $18 \%$ of the total number of students at CUMe participated in this survey. Regarding the gender, 54 students were female, 45 were male and one of them did not specify it. The nationalities of the recruited students were not determined in this survey but, in general, the students were Spanish. Figure 1 depicts the number of participants according to their ages. One can see that most of the recruited students are 25 years old or younger (88\%), $9 \%$ are in the range between 26 and 40 years old, and $3 \%$ are over 40 years old. The participants were undergraduates from diverse disciplines: Industrial Design (41\%), Nursing (24\%), Computing Engineering (14 \%), Geomatics and Topography (9\%), Telematics (5\%), Double Degree in Computing Engineering and Telematics (4\%), and not specified (3\%). We highlight that not all degrees offered by the CUMe include environmental contents. Nevertheless, CUMe often organizes talks and activities on climate change. 


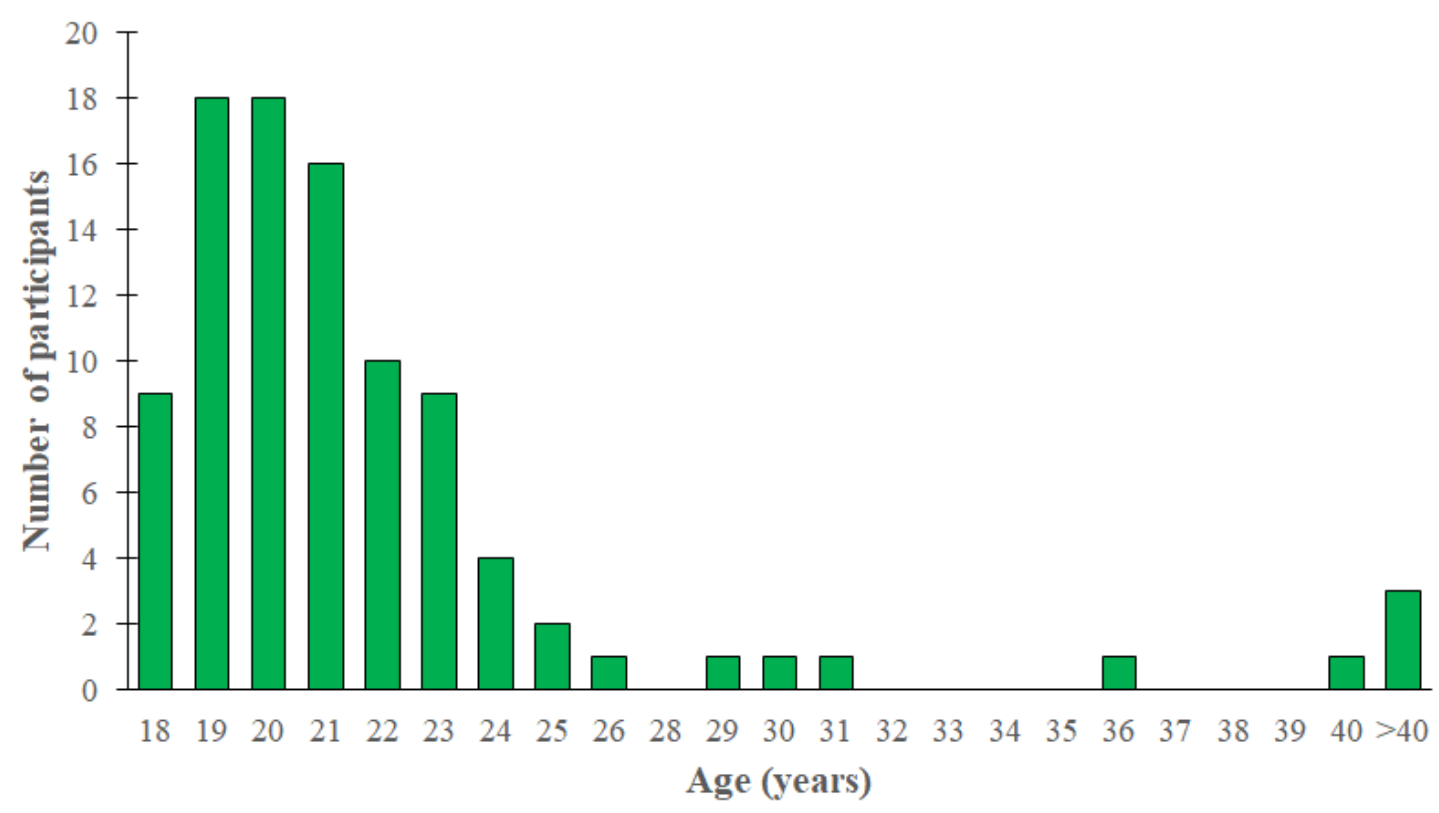

Figure 1. Number of participants as a function of the age range.

The students were contacted to participate in this study by instant messaging services and e-mails where a link to an online questionnaire was included. We decided to use this method as several works showed that online surveys are effective in limiting social desirability bias (Tourangeau et al., 2000; Krumpal, 2013). The survey took around 3 minutes to be completed, the only language used in it was Spanish, and the participants did not receive any incentives. The form contained four questions following the survey carried out by von Storch et al. (2019):

- Is climate change happening right now by natural or anthropogenic causes? (Responses: 1- not at all; 7- very much).

- Is climate change a serious and dangerous threat to humanity? (Responses: 1- not at all; 7- very much).

- Do you think that recent or next future climate change is mainly caused by human action? (Responses: 1- not at all; 7- very much).

- In your opinion, what is the most important task that the climate scientific community faces? (Responses: i. to define the climate problems and to attribute climate change cause; ii. to provide solutions to climate change; and iii. to motivate society to act on climate change). 


\section{Analysis of results}

Most of the students at CUMe that participated in this survey agreed that climate change is happening right now by either natural or anthropogenic causes (Figure 2). In fact, $65 \%$ of the respondents consider it as "very much". This is a slightly lower percentage than that found in the Hamburg survey (76 \%) but greater than in Qingdao (47.6 \%). Regarding responses 5-7 as agreement, $96 \%$ in CUMe are in agreement. This is slightly greater than those percentages found in Hamburg (91\%) and Qingdao (82 \%). Then, our results are very similar to those found in the Hamburg study.

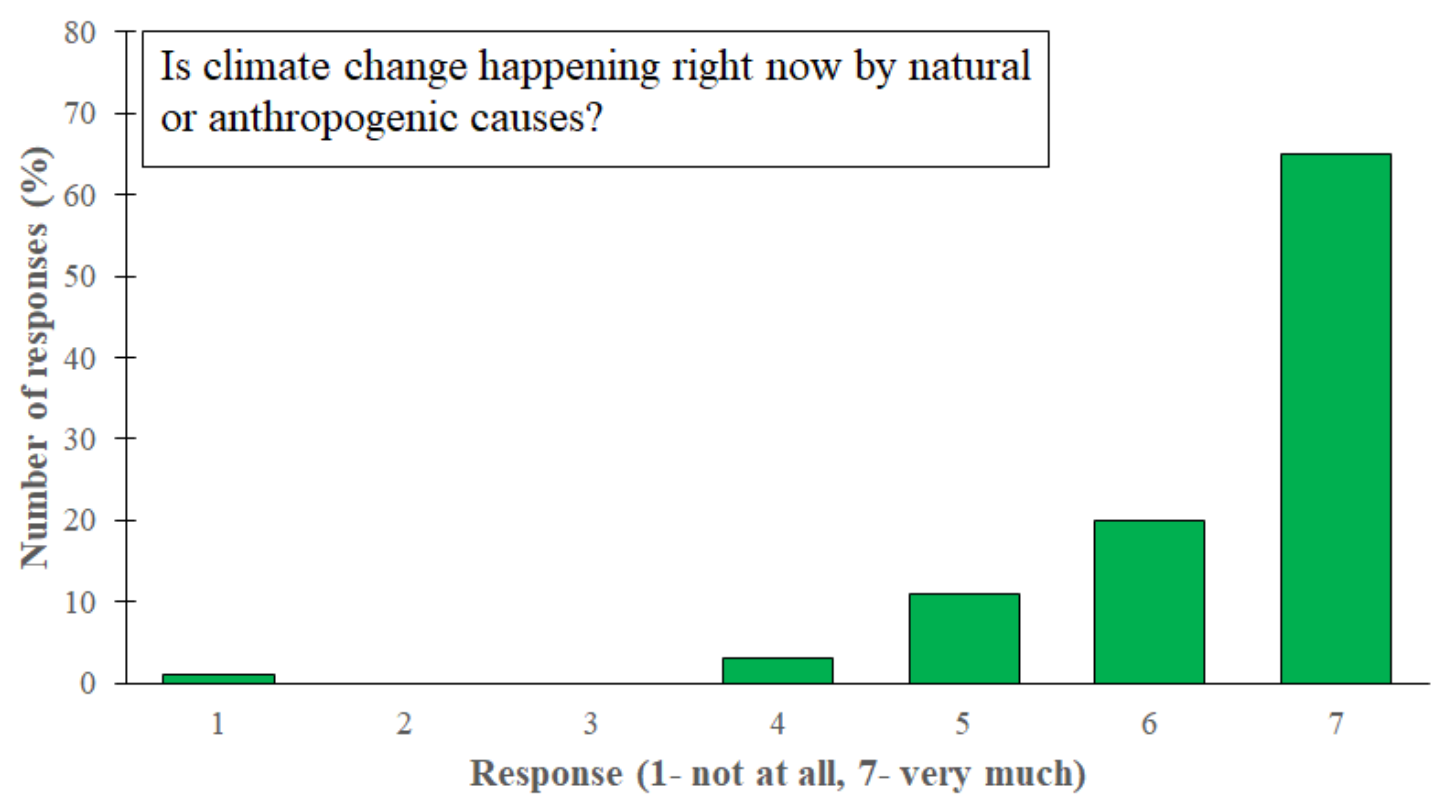

Figure 2. Percentage of responses from 1 (not at all) to 7 (very much) to the question "Is climate change happening right now by natural or anthropogenic causes?".

According to the second question raised in the previous section, students in CUMe also considered that climate change is a serious, dangerous threat to humankind (Figure 3). The answer "very much" was chosen by $70 \%$. This value is significantly greater than those found in the Hamburg (48\%) and Qingdao (39.8\%) surveys. We also obtained $96 \%$ considering answers 5-7 while $86.7 \%$ and $74.7 \%$ were obtained in the Hamburg and Qingdao surveys, respectively. 


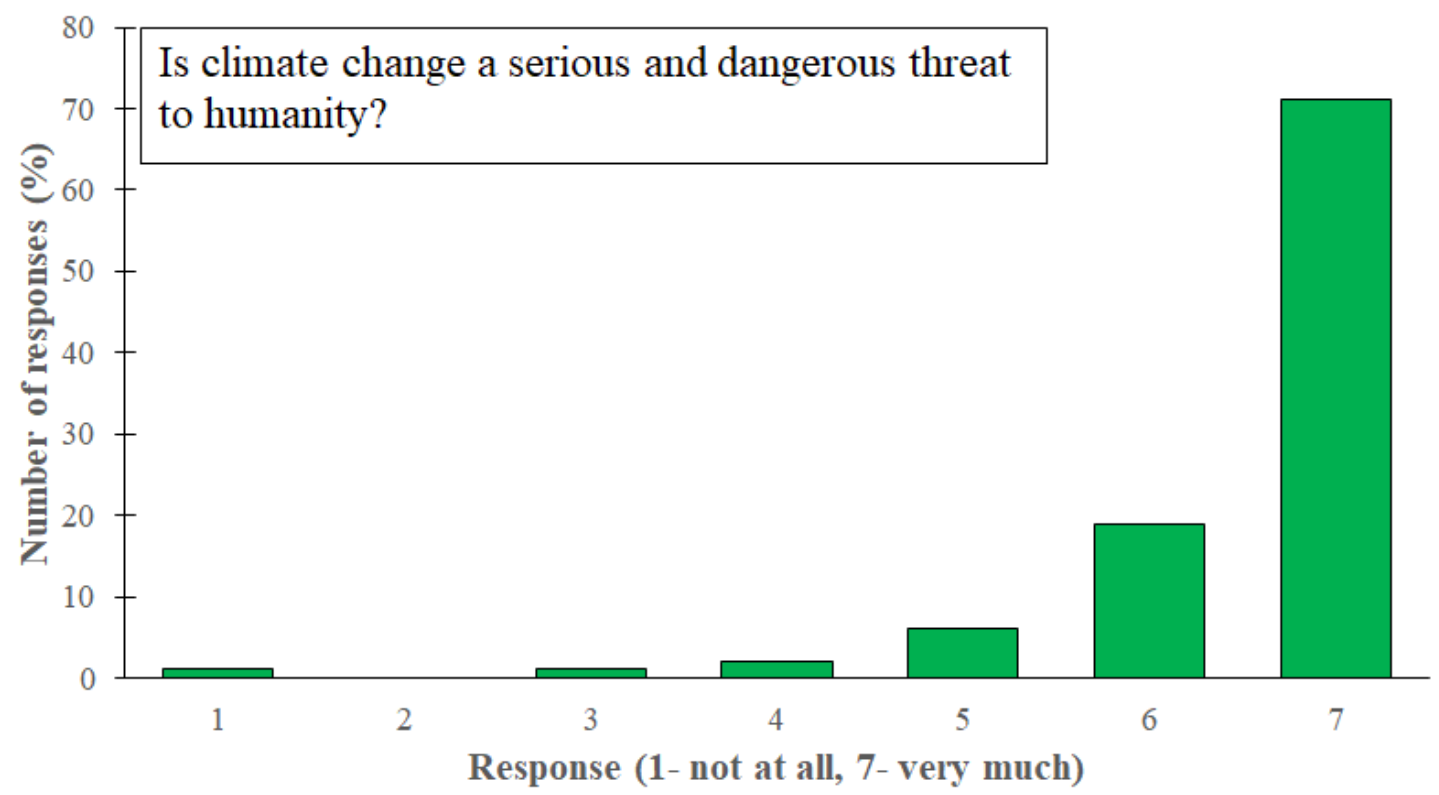

Figure 3. Percentage of responses from 1 (not at all) to 7 (very much) to the question "Is climate change a serious and dangerous threat to humanity?".

The vast majority of students from CUMe considered that climate change has its origin in the human action (Figure 4). Thus, $54 \%$ of the students from CUMe rates it as "7- very much" and $96 \%$ in the range 5-7 which is in agreement with other works (Cook et al., 2016). These results are similar to those found in the Hamburg study as the range 5-7 was selected by $94 \%$ and the option "7- very much" by around 45 $\%$. This latter value is slightly lower than that obtained in our work. Although the majority of Qingdao students also thought that climate change is due to anthropogenic causes (71 \% in the range 5-7), only around 20 \% chose "7- very much". Both percentages are significantly lower than those found in Hamburg and Spain. 


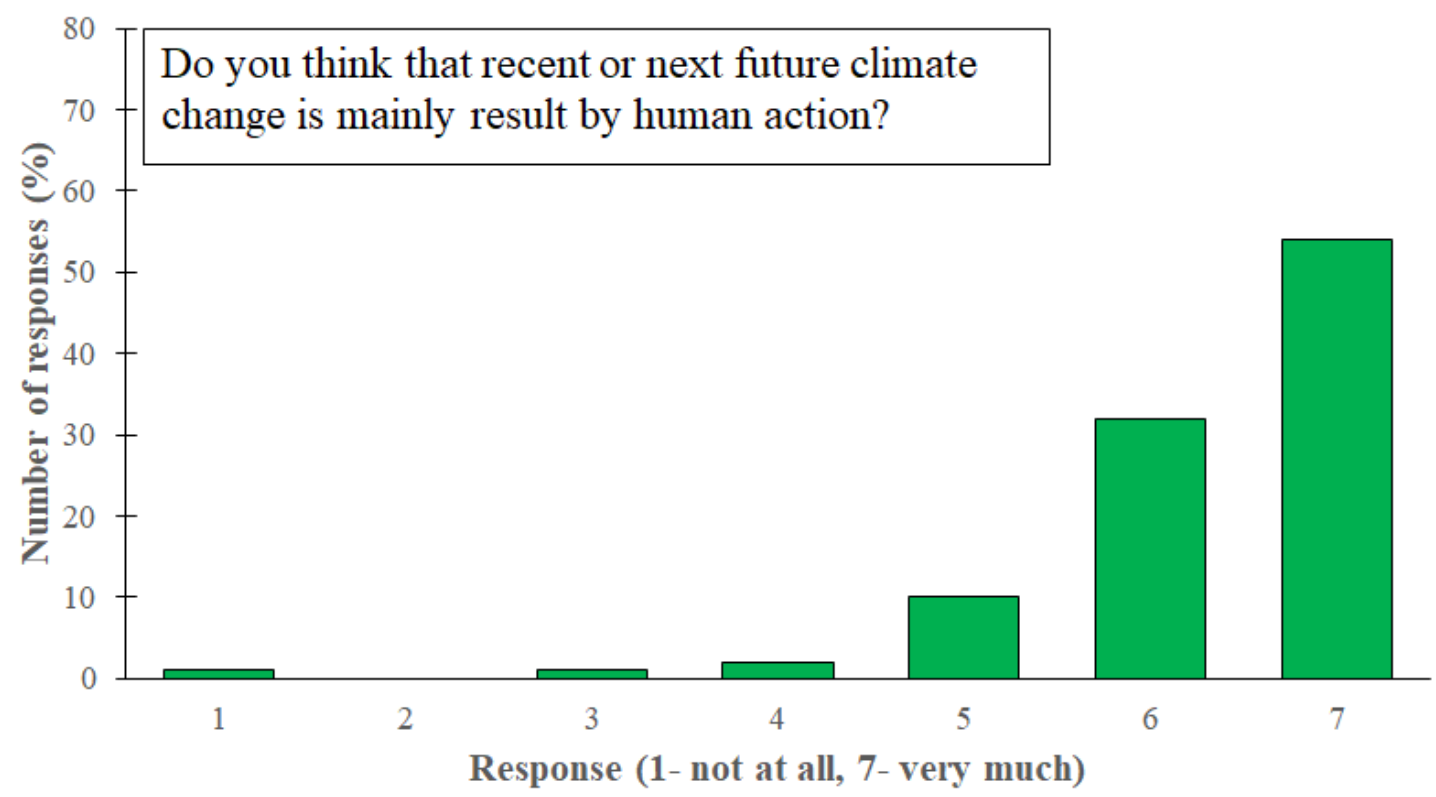

Figure 4. Percentage of responses from 1 (not at all) to 7 (very much) to the question "Do you think that recent or next future climate change is mainly result by human action?".

Students in Mérida believed that the main task facing the climate scientific community is to motivate people to act on climate change (56\%). Other significant part considered that the most important task for scientists is to provide solutions on climate change (38\%). Only $6 \%$ of participants indicated that scientists must define the problems on climate change and to attribute causes. Figure 5 includes these results. Our values are similar to those found by von Storch et al. (2019) in Hamburg: 52 \% motivation, 32 $\%$ solutions, and $16 \%$ attribution. However, they differ significantly from those obtained from Qingdao data. For Qingdao students, the most important task is to define problems on climate change and to attribute causes (44\%), then the second and third tasks are "motivation" (around $35 \%$ ) and "solutions" (around $18 \%$ ). Thus, students in Qingdao thought that scientists must adopt the role of showing the empirical evidence and motivating to act on climate change but the solutions must be carried out politically. However, the results from Mérida and Hamburg indicate the general belief that problems are already identified by scientists and that now they must also be an active part in solutions and motivation of people. 


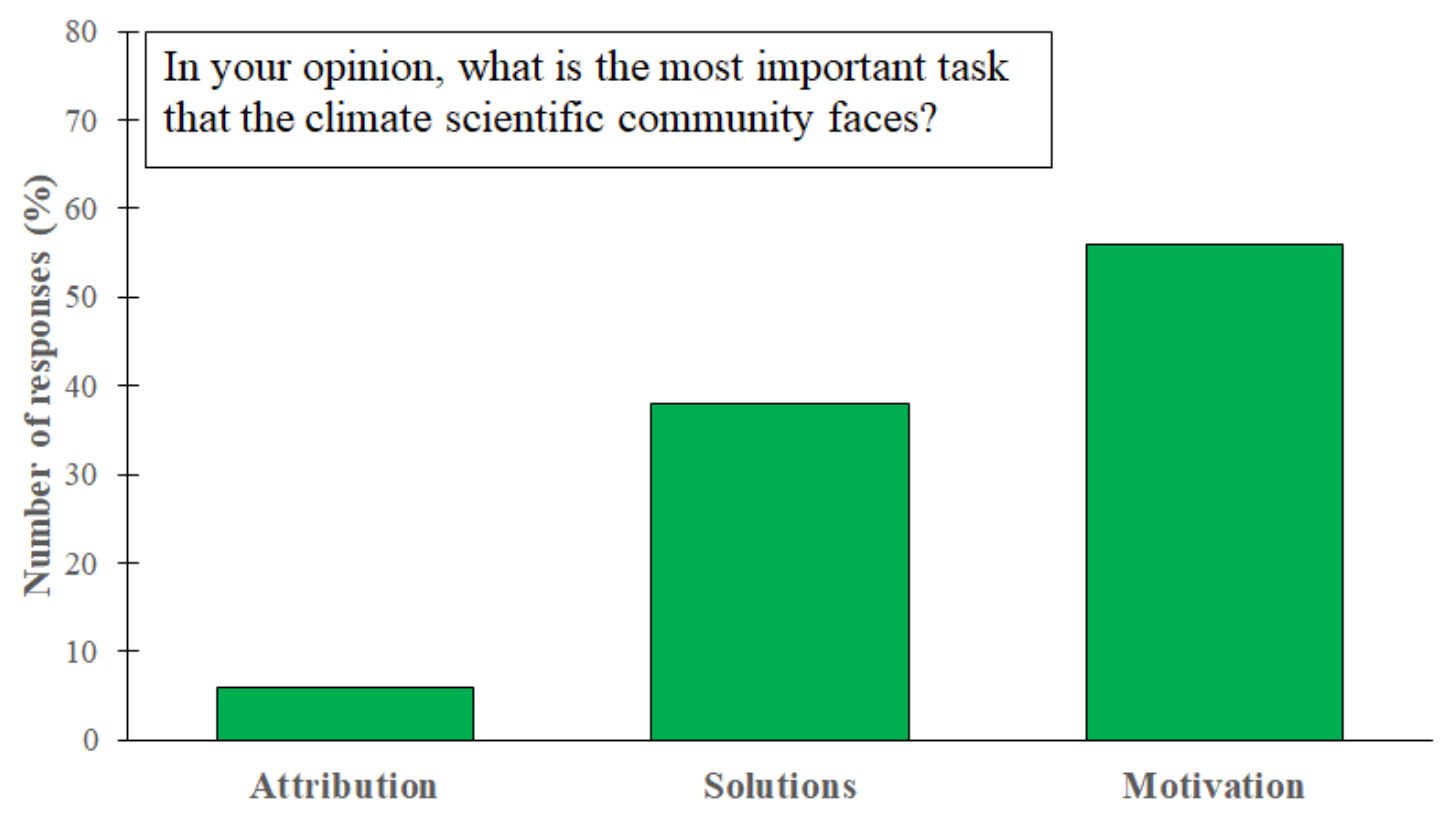

Figure 5. Percentage of responses associated to "Attribution", "Solutions", and "Motivation" to the question "In your opinion, what is the most important task that the climate scientific community faces?".

\section{Final comments}

We have carried out a survey on the attitudes of the students at CUMe in Mérida (SW Spain) on climate change following the work made by Storch et al. (2019) with students in Hamburg (Germany) and Qingdao (China). We have recruited 100 students to complete a questionnaire in order to know about the opinions of the participants on this important challenge for our society. Most of them are young students and they study diverse disciplines. According to our results, the vast majority of the respondents considered that climate change is happening right now, that it is a serious and dangerous threat for humanity, and that it is of anthropogenic origin. Furthermore, the students at CUMe think that the most important task for the scientific community is to motivate people to act on climate change and to provide solutions. We acknowledge that the number of participants in this survey is low and could not represent all the youth of Spain or even of the region of Extremadura, where Mérida is located. Thus, more studies in this way would be needed to confirm our results. 
Our results agree with those found by von Storch et al. (2019) for students in Hamburg. Even we found higher percentages in answers "7- very much". Thus, our study also contains some differences with Qingdao survey. In addition, participants both from Mérida and Hamburg believe that the most important tasks for the scientific community are to motivate people to act against climate change and to provide solutions, in that order. Instead, it is the definition of the problems on climate change and to attribute causes according to Qingdao students. In addition, there are some differences between our study and the one made by Storch et al. (2019). While students from diverse disciplines participated in our study, only students related to environmental sciences were recruited in Storch et al. (2019). We think that our percentages in answers "7- very much" could be even greater if we had restricted this survey to environmental sciences students exclusively. Some small differences were found between percentages in answers "7- very much" from Mérida and Hamburg that can be attributed to the temporal difference between both studies. Hamburg survey was carried out in June 2017, while Mérida one in November 2020. Several important global social movements to act against climate change have recently emerged. Some examples are "Fridays for Future" and the Climate Summit COP25 in Madrid (Spain). This can explain those small differences between the studies in Mérida and Hamburg.

In conclusion, our results agree with von Storch et al. (2019). Students in Mérida and Hamburg, both from European countries, have similar opinions which are somewhat different from Qingdao students from China. Thus, cultural habits could explain the differences found in these surveys.

\section{Acknowledgements}

The authors acknowledge the implication of the students at the Mérida University Center in this survey. 


\section{References}

Bray, D., von Stoch, H., 1999. Climate Science: An Empirical Example of Postnormal Science. Bull. Am. Meteorol. Soc. 80, 439-455.

Bray, D., von Stoch, H., 2016. The Bray and von Storch 5th international survey of climate scientists 2015/2016. HZG Report 2016-2.

Cook, J., et al., 2016. Consensus on consensus: a synthesis of consensus estimates on human-caused global warming. Environ. Res. Lett. 11, 048002. DOI: 10.1088/1748-9326/11/4/048002.

IPCC, 2014. Climate Change 2014: Synthesis Report. Contribution of Working Groups I, II and III to the Fifth Assessment Report of the Intergovernmental Panel on Climate Change. Geneva, Switzerland.

Krumpal, I., 2013. Determinants of social desirability bias in sensitive surveys: a literature review. Qual. Quant. 47, 2025-2047. DOI: 10.1007/s11135-011-9640-9.

Llorente, C., Revuelta, G., Carrió, M., 2020. Social participation in science: Perspectives of Spanish civil society organizations. Public Understanding of Science. DOI: 10.1177/0963662520960663

Ratter, B.M.W., Philipp, K.H.I., von Storch, H., 2012. Between hype and decline e recent trends in public perception of climate change. Environ. Sci. Policy 18, 3-8. DOI: 10.1016/j.envsci.2011.12.007.

von Storch, H., Chen, X.E., Pfau-Effinger, B., Bray, D., Ullmann, A., 2019. Attitudes of young scholars in Qingdao and Hamburg about climate change and climate policy - The role of culture for the explanation of differences. Advances in Climate Change Research 10, 158-164. DOI: 10.1016/j.accre.2019.04.001.

Tourangeau, R., Rips, L.J., Rasinski, K., 2000. The Psychology of Survey Response. Cambridge University Press, Cambridge.

Yu, H., Wang, B., Zhang, Y.-J., et al., 2013. Public perception of climate change in China: results from the questionnaire survey. Nat. Hazards 69, 459-472. DOI: 10.1007/s11069-013-0711-1. 